\title{
Workshop on Numerical Ecology
}

An Advanced Research Workshop on Numerical Ecology, sponsored by NATO Scientific Affairs Division, will be held in Roscoff (Brittany, France) from June 2 (arrival) to June 12 (departure), 1986. Fourty community ecologists, well-trained in statistics, will be given the opportunity to explore recent developments in mathematics, presented during the morning sessions by mathematicians and methodologists. Subjects include: fractal theory, scaling techniques, nonlinear multivariate analysis with optimal scaling, clustering with models, spatial analysis, and qualitative path analysis. Working groups will meet during the afternoons to examine how to apply these mathematical methods to the study of ecosystems. The working groups will focus on: 1) Micro-organisms; 2) Benthic communities; 3) Pelagic communities; 4) Dynamic biological oceanography and limnology; 5) Terrestrial vegetation; 6) Terrestrial fauna. Participation will be mostly by invitation.

Besides the list of invited participants, community ecologists who are trained in multivariate statistics or data analysis are invited to apply. A limited number of participants will be selected by the International Organising Committee, on the basis of: 1) their potential contribution to the success of the Workshop (judgement based on the list and pertinence of their recent publications); 2) the distribution by countries of origin; 3 ) the distribution by fields of specialty, given the six working groups listed above. Application files should contain information on these three points; microbial community ecologists are especially invited to apply. A few self-supported observers may be accepted for the morning sessions. Applications should be sent before December 20, 1985, to: Dr. Pierre Legendre, Département de Sciences biologiques, Université de Montréal, C.P. 6128, Succursale A, Montréal, Québec H3C 3J7 (Canada). 